\title{
CPHLN recommendations for the laboratory detection of Shiga toxin-producing Escherichia coli (O157 and non-O157)
}

\author{
L Chui ${ }^{1 *}$, S Christianson², DC Alexander ${ }^{3}$, V Arseneau 4 , S Bekal 5 , B Berenger ${ }^{1}$, Y Chen 6 , \\ R Davidson ${ }^{7}$, DJ Farrell ${ }^{8}$, GJ German ${ }^{4}$, L Gilbert ${ }^{9}$, LMN Hoang ${ }^{10}$, RP Johnson ${ }^{2}$, A MacKeen ${ }^{11}$,
} A Maki ${ }^{6}, \mathrm{C}$ Nadon ${ }^{2}$, E Nickerson ${ }^{12}$, A Peralta ${ }^{6}$, SM Radons Arneson ${ }^{11}, \mathrm{Y} \mathrm{Yu}^{6}$, K Ziebell ${ }^{2}$ on behalf of Canadian Public Health Laboratory Network (CPHLN)

\section{Abstract}

Shiga toxin-producing Escherichia coli (STEC) are important enteric pathogens responsible for sporadic cases and outbreaks of gastroenteritis. E.coli O157:H7/NM (STEC O157) are the most commonly known STEC serotypes but it is now increasingly apparent that non-O157 STEC serotypes have been underreported in the past because they were not part of routine screening in many front-line laboratories. The Canadian Public Health Laboratory Network (CPHLN) has identified the need for improved detection and surveillance of non-O157 STEC and has developed the following recommendations to assist in the decision-making process for clinical and reference microbiology laboratories. These recommendations should be followed to the best of a laboratory's abilities based on the availability of technology and resources.

The CPHLN recommends that when screening for the agents of bacterial gastroenteritis from a stool sample, front-line laboratories use either a chromogenic agar culture or a culture-independent diagnostic test (CIDT). CIDT options include nucleic acid amplification tests (NAATs) to detect Shiga toxin genes or enzyme immunoassays (EIAs) to detect Shiga toxins. If either CIDT method is positive for possible STEC, laboratories must have a mechanism to culture and isolate STEC in order to support both provincial and national surveillance as well as outbreak investigations and response. These CPHLN recommendations should result in improved detection of STEC in patients presenting with diarrhea, especially when due to the non-O157 serotypes. These measures should enhance the overall quality of healthcare and food safety, and provide better protection of the public via improved surveillance and outbreak detection and response.
Suggested citation: Chui L, Christianson S, Alexander DC, Arseneau V, Bekal S, Berenger B, Davidson R, Farrell DJ, German GJ, Gilbert L, Hoang LMN, Johnson RP, MacKeen A, Maki A, Nadon C, Nickerson E, Peralta A, Radons Arneson SM, Yu Y, Ziebell K on behalf of Canadian Public Health Laboratory Network (CPHLN). CPHLN recommendations for the laboratory detection of Shiga toxin-producing Escherichia coli (O157 and non-O157). Can Commun Dis Rep 2018;44(11):304-7. https://doi.org/10.14745/ccdr.v44i11a06

Keywords: Laboratory testing recommendations, Shiga toxin-producing Escherichia coli, O157 STEC, non-O157 STEC, culture independent diagnostic tests, nucleic acid amplification tests (NAATs), enzyme immunoassays (EIAs), chromogenic agar culture

\author{
Affiliations \\ 1 Provincial Laboratory for \\ Public Health, Alberta Public \\ Laboratories, $A B$ \\ ${ }^{2}$ National Microbiology \\ Laboratory, MB \& ON \\ ${ }^{3}$ Cadham Provincial Laboratory, \\ MB \\ ${ }^{4}$ Health Prince Edward Island, PE \\ ${ }^{5}$ Laboratoire de Santé Publique \\ du Québec, QC \\ ${ }^{6}$ Public Health Ontario, ON \\ ${ }^{7}$ Queen Elizabeth II Health \\ Science Centre, NS \\ ${ }^{8}$ Roy Romanow Provincial \\ Laboratory, SK \\ 9 Provincial Public Health and \\ Microbiology Laboratory, Eastern \\ Health, NL \\ ${ }^{10}$ BC Centre for Disease Control \\ Public Health Laboratory, BC \\ ${ }^{11}$ Canadian Public Health \\ Laboratory Network, MB \\ 12 The New Brunswick Enteric \\ Reference Centre, NB
}

\section{${ }^{\star}$ Correspondence:}

linda.chui@ahs.ca

\section{Introduction}

Escherichia coli are part of the normal flora of the gut. However, Shiga toxin-producing Escherichia coli (STEC) are intestinal pathogens. Although they typically cause a self-limited episode of diarrhea and abdominal pain, on rare occasions they cause severe-and potentially fatal—sequelae such as hemolytic uremic syndrome (1).
E. coli O157:H7/NM (STEC O157) are the most common STEC serotypes causing infection in humans, but many non-O157 STEC serotypes have been associated with serious illness and major outbreaks (2). In 2011 there was a European outbreak of E. coli O104:H4 (3). In 2016, there was an outbreak in Canada and the United States of STEC 0121 infections associated with flour (4). 
These recent outbreaks of non-O157 serotypes have highlighted the clinical importance of timely and reliable detection and surveillance of these organisms (5-10).

In 2016, 642 cases of STEC infections were reported to the Canadian National Enteric Surveillance Program (NESP); approximately 35\% were caused by non-O157 STEC (11). Current data for Canada on non-O157 STEC infections are likely an underestimate as they are not part of routine screening in many laboratories $(11,12)$. There are several reasons for this gap. STEC 0157 is readily identified using differential and selective media such as Sorbitol-MacConkey agar and chromogenic O157 agar. Unlike 0157 STEC, non-O157 STEC lack the phenotypic characteristics that readily distinguish them from generic E. coli, making culture-based isolation challenging.

\section{Detection of non-0157 STEC subtypes}

Improvements to laboratories' ability to identify non-O157 STEC are based on the use of chromogenic and/or selective agars and culture-independent diagnostic tests (CIDT). The two common CIDTs include nucleic acid amplification tests (NAATs) for detection of Shiga toxin genes, and enzyme immunoassays (EIAs) that detect Shiga toxins. Less common CIDTs include Shiga toxin detection by cell culture cytotoxicity assays or reverse passive latex agglutination test, and isolation of selected serogroups by $\mathrm{O}$-antigen immunomagnetic bead-capture methods. However, these methods are not practical in most front-line microbiology laboratories. Not only is it important to identify the STEC subtype, it is also essential to have isolates for further characterization such as serotyping, molecular genotyping and whole genome sequencing.

Each detection method has its advantages and disadvantages. Chromogenic agar has a sensitivity of greater than $85 \%$ (13). It is less costly than other methods and can be easily substituted into a laboratory's workflow by replacing the current 0157 specific plates. However, chromogenic agar can be inhibitory to some STEC serotypes (14). As for the detection of Shiga toxins by EIA, both microwell and lateral flow formats are available. The sensitivity of EIAs is lower for direct stool testing; however, overnight enrichment in MacConkey broth (15) or other suitable broth may provide sensitivity approaching that of NAATs $(13,16)$. Both in-house and commercial NAATs have equivalent sensitivities and are the most sensitive methods available $(15,17)$. Many NAATs can be performed directly on stool samples (18), improving the turn-around time compared to culture and EIA. Multiplex NAATs have the added advantage of detecting multiple pathogens concurrently. Both EIAs and NAATs will detect Shiga toxins and Shiga toxin genes respectively from any serotype of STEC. However, EIAs and NAATs are more expensive than agar for screening. NAATs also require laboratories to purchase additional equipment, designated space for molecular set-up and specialized training of personnel, which may be impractical for many frontline laboratories.

\section{Public health implications}

Isolation and further subtyping enables the comparison of STEC strains in order to identify outbreaks and potential sources of infection. Once the suspected source of the outbreak is identified, tracing and outbreak management activities by public health officials can prevent further transmission and promote public awareness.

The objectives of the following recommendations are to identify laboratory choices in a testing workflow for the detection, confirmation of STEC in stool specimens, and recovery of positive isolates for further characterization.

\section{Recommendations}

The Canadian Public Health Laboratory Network (CPHLN) recommends that when screening for the agents of bacterial gastroenteritis, front-line laboratories use one or more of three options for the detection of STEC: NAAT, culture on selective agar, or broth enrichment plus an EIA (Figure 1). Stool specimens submitted for STEC detection should follow local guidelines for submission and testing. Laboratories using chromogenic agar as their primary screening method may consider using an EIA method with broth enrichment or a NAAT in selected cases where there is a high suspicion of STEC infection and chromogenic agar results are negative.

If CIDT is implemented for STEC testing, culture is still recommended for the recovery of isolates for further characterization when Shiga toxins or Shiga toxin genes are identified. CPHLN culture recommendations following CIDT can be found in Berenger et al. (19). It is imperative that front-line laboratories communicate with their referral public health laboratories to determine the required work-up for culture, isolation or characterization of isolates before submitting any samples.

\section{Discussion}

To accurately diagnose all STEC-related cases of gastroenteritis that may lead to outbreaks and have public health implications, it is important that both 0157 and non-O157STEC serotypes are identified. To facilitate this, screening should be done using either culture or CIDT by a NAAT or an EIA. If the CIDT is positive for possible STEC, then culture is needed for STEC confirmation and characterization.

Laboratories should follow the CPHLN recommendations to the best of their abilities based on the availability of technology and resources. It is important to emphasize that when STEC are detected, culturing the organism is of paramount importance for further characterization (typing and subtyping), as well as 
Figure 1: Recommendations for the detection of Shiga toxin-producing Escherichia coli in stool specimens

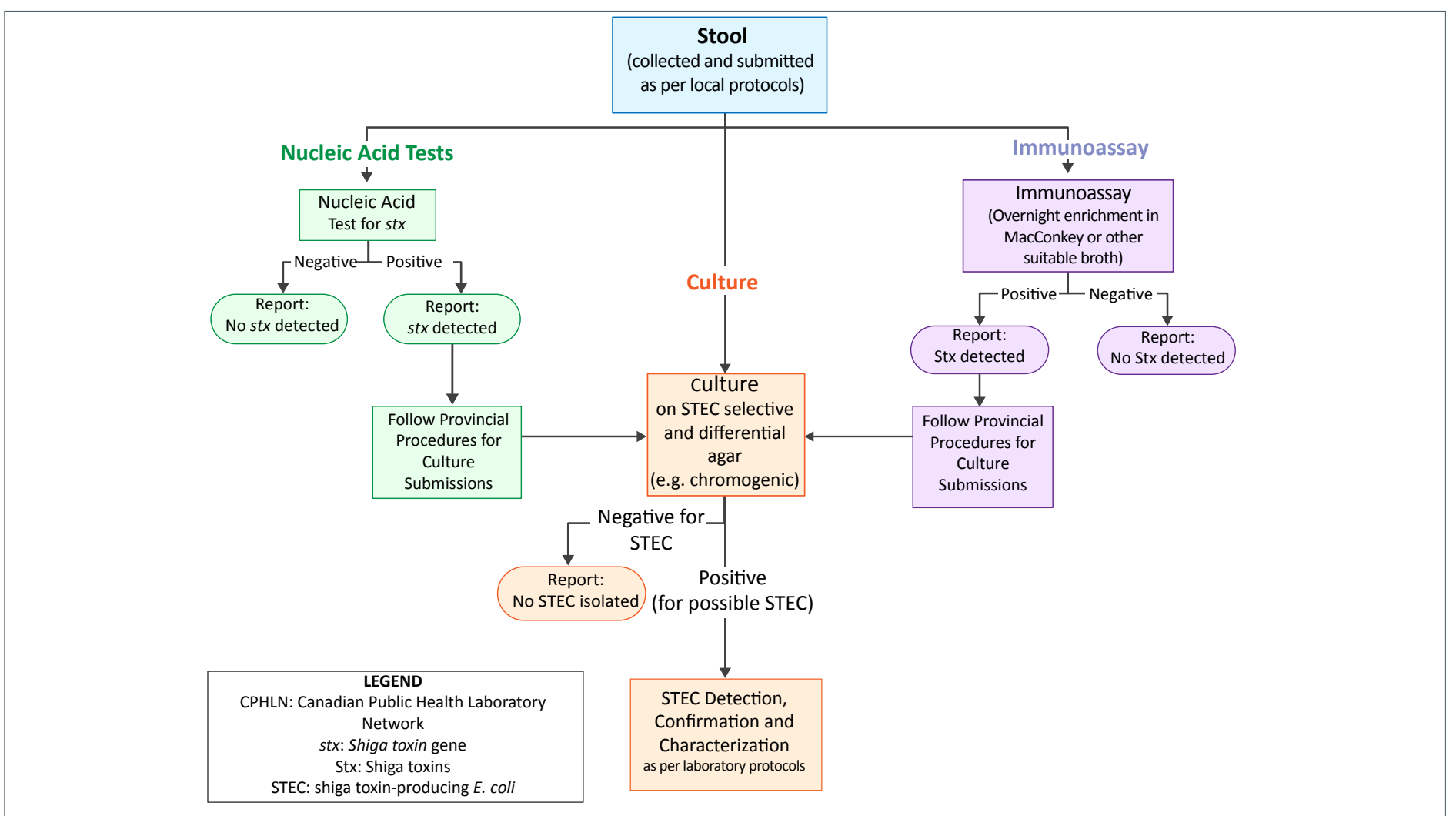

to facilitate the outbreak response and support surveillance programs, including PulseNet Canada and the National Enteric Surveillance Program.

The role of the provincial or federal laboratories is to support front-line laboratories by performing confirmatory testing as necessary, as well as serotyping and other reference laboratory services for STEC isolates. These laboratories are also available to assist with facilitating the implementation of these new testing algorithms for non-O157 STEC. The public health laboratory system varies among provinces; so any changes in public health laboratory protocols that may impact the capacity of front-line laboratories to follow these recommendations must be discussed with the front-line laboratories and other stakeholders prior to implementation.

\section{Conclusion}

Following these CPHLN recommendations should result in improved detection of STEC in patients presenting with diarrhea, especially the non-O157 serotypes. These measures will enhance the overall quality of health care and food safety, and provide better protection of the public via improved surveillance, and outbreak detection and response.

\section{Authors' statement}

All authors are members of the Canadian Public Health Laboratory Network (CPHLN) Shiga toxin-producing
Escherichia coli (STEC) Working Group. This group was chaired by L Chui (Provincial Co-Chair) and S Christianson (Federal Co-Chair).

\section{Conflict of interest}

None.

\section{Acknowledgements}

The authors would like to acknowledge members of the Canadian Public Health Laboratory Network, Laboratory Directors Council and Secretariat support for their advice and guidance in the development of this recommendation.

\section{Funding}

Funding for the Canadian Public Health Laboratory Network Secretariat is provided by the National Microbiology Laboratory of the Public Health Agency of Canada.

\section{References}

1. Rahal EA, Kazzi N, Nassar FJ, Matar GM. Escherichia coli O157:H7-Clinical aspects and novel treatment approaches. Front Cell Infect Microbiol 2012 Nov;2:138. DOl PubMed 


\section{GUIDANCE}

2. Rounds JM, Rigdon CE, Muhl LJ, Forstner M, Danzeisen GT, Koziol BS, Taylor C, Shaw BT, Short GL, Smith KE. Non-O157 Shiga toxin-producing Escherichia coli associated with venison. Emerg Infect Dis 2012 Feb;18(2):279-82.

DOI PubMed

3. Buchholz $U$, Bernard $H$, Werber D, Böhmer MM, Remschmidt C, Wilking $\mathrm{H}$, Deleré $\mathrm{Y}$, an der Heiden $\mathrm{M}$, Adlhoch $\mathrm{C}$, Dreesman J, Ehlers J, Ethelberg S, Faber M, Frank C, Fricke G, Greiner M, Höhle M, Ivarsson S, Jark U, Kirchner M, Koch J, Krause G, Luber P, Rosner B, Stark K, Kühne M. German outbreak of Escherichia coli O104:H4 associated with sprouts. N Engl J Med 2011 Nov;365(19):1763-70. DOI PubMed

4. Morton V, Cheng JM, Sharma D, Kearney A. An outbreak of Shiga toxin-producing Escherichia coli O121 infections associated with flour-Canada, 2016-2017. Can Commun Dis Rep 2017 Jul;43(7/8):154-5. DOI PubMed

5. Thompson LH, Giercke S, Beaudoin C, Woodward D, Wylie JL. Enhanced surveillance of non-O157 verotoxin-producing Escherichia coli in human stool samples from Manitoba. Can $\mathrm{J}$ Infect Dis Med Microbiol 2005 Nov; 16(6):329-34. DOI PubMed

6. Hughes JM, Wilson ME, Johnson KE, Thorpe CM, Sears $\mathrm{CL}$. The emerging clinical importance of non-O157 Shiga toxin-producing Escherichia coli. Clin Infect Dis 2006 Dec;43(12):1587-95. DOI PubMed

7. Centers for Disease Control and Prevention (CDC). Laboratory-confirmed non-O157 Shiga toxin-producing Escherichia coli--Connecticut, 2000-2005. MMWR Morb Mortal Wkly Rep 2007 Jan;56(2):29-31. PubMed

8. Chui L, Lee MC, Malejczyk K, Lim L, Fok D, Kwong P. Prevalence of shiga toxin-producing Escherichia coli as detected by enzyme-linked immunoassays and real-time PCR during the summer months in northern Alberta, Canada. J Clin Microbiol 2011 Dec;49(12):4307-10. DOI PubMed

9. Couturier MR, Lee B, Zelyas N, Chui L. Shiga-toxigenic Escherichia coli detection in stool samples screened for viral gastroenteritis in Alberta, Canada. J Clin Microbiol 2011 Feb;49(2):574-8. DOI PubMed

10. Gould LH, Mody RK, Ong KL, Clogher P, Cronquist AB, Garman KN, Lathrop S, Medus C, Spina NL, Webb TH, White PL, Wymore K, Gierke RE, Mahon BE, Griffin PM; Emerging Infections Program Foodnet Working Group. Increased recognition of non-O157 Shiga toxin-producing Escherichia coli infections in the United States during 2000-2010: epidemiologic features and comparison with E. coli O157 infections. Foodborne Pathog Dis 2013 May; 10(5):453-60. DOI PubMed
11. Government of Canada. National Enteric Surveillance Program (NESP): Annual summary 2016. Ottawa (ON): Public Health Agency of Canada; 2018. http://publications.gc.ca/ collections/collection_2018/aspc-phac/HP37-15-2016-eng. pdf

12. Government of Canada. National Enteric Surveillance Program (NESP): Annual summary 2013. Ottawa (ON): Public Health Agency of Canada; 2015. http://publications.gc.ca/ collections/collection_2016/aspc-phac/HP37-15-2013-eng. pdf

13. Parsons BD, Zelyas N, Berenger BM, Chui L. Detection, characterization, and typing of Shiga toxin-producing Escherichia coli. Front Microbiol 2016 Apr;7:478.

DOI PubMed

14. Zelyas N, Poon A, Patterson-Fortin L, Johnson RP, Lee W, Chui L. Assessment of commercial chromogenic solid media for the detection of non-O157 Shiga toxin-producing Escherichia coli (STEC). Diagn Microbiol Infect Dis 2016 Jul;85(3):302-8. DOI PubMed

15. Chui L, Patterson-Fortin L, Kuo J, Li V, Boras V. Evaluation of enzyme immunoassays and real-time PCR for detecting Shiga toxin-producing Escherichia coli in Southern Alberta, Canada. J Clin Microbiol 2015 Mar;53(3):1019-23.

DOI PubMed

16. Jassem AN, Chou FY, Yang C, Croxen MA, Pintar KD, Paccagnella A, Hoang L, Prystajecky N. Pooled nucleic acid amplification test for screening of stool specimens for Shiga toxin-producing Escherichia coli. J Clin Microbiol 2016 Nov;54(11):2711-5. DOI PubMed

17. Reddington K, Tuite N, Minogue E, Barry T. A current overview of commercially available nucleic acid diagnostics approaches to detect and identify human gastroenteritis pathogens. Biomol Detect Quantif 2014 Aug;1(1):3-7. DOI PubMed

18. Holland JL, Louie L, Simor AE, Louie M. PCR detection of Escherichia coli O157:H7 directly from stools: evaluation of commercial extraction methods for purifying fecal DNA. J Clin Microbiol 2000 Nov;38(11):4108-13. PubMed

19. Berenger $B$, Chui $L$, Reimer $A R$, Allen $V$, Alexander $D$, Domingo MC, Haldane D, Hoang L, Levett P, MacKeen A, Marcino D, Sheitoyan-Pesant C, Zahariadis G; Canadian Public Health Laboratory Network. Canadian Public Health Laboratory Network position statement: non-culture based diagnostics for gastroenteritis and implications for public health investigations. Can Commun Dis Rep 2017 Dec;43(12):279-81. DOI PubMed 